\title{
The Usage of loT and far off Sensor Associations and their Application in Horticulture for the Improvement of Yield Efficiency in India
}

PRATIK CHOKHOBA GHUTKE ( $\square$ pcghutke2214@gmail.com )

Tulsiramji Gaikwad-Patil College of Engineering and Technology https://orcid.org/0000-0002-33794420

\section{Rahul Agrawal}

Sandip University

\section{Research Article}

Keywords: Internet of Things, smart Agriculture Framework, Wireless Sensors Network, Smart farm

Posted Date: April 19th, 2021

DOI: https://doi.org/10.21203/rs.3.rs-397833/v1

License: (c) (i) This work is licensed under a Creative Commons Attribution 4.0 International License.

Read Full License 


\section{The usage of IoT and far off sensor associations and their application in horticulture for the improvement of yield efficiency in India}

\author{
Pratik C. Ghutke \\ Department of Electrical Engineering \\ Tulsiramji Gaikwad-Patil College of Engineering \\ RTMN University, Nagpur (M.S) India \\ pcghutke2214@gmail.com \\ https://orcid.org/0000-0002-3379-4420
}

\author{
Dr. Rahul Agrawal \\ Department of Electrical Engineering \\ School of Engineering and Technology \\ Sandip University, Nashik (M.S) India \\ yourrahul11@gmail.com
}

\begin{abstract}
In the development of mortal civilization, farming assumes a key part. Individuals are taking a stab at giving extra endeavor likewise extraordinary ways to deal with duplicate food presentation as a result of the expanded interest for food. One such activity is the utilization of different advances for horticulture. As IoT sensors are equipped for giving horticultural field data and afterward following up based on crack information, keen cultivating is an arising term. The rising need of sustenance, in respects with total and greatness, has expanded the interest for the farming area to heighten and industrialize. The IoT is a very reassuring family of robotizations having able in giving various answers for rural modernization In this work, the development of a wise ranch structure utilizing the guaranteed winner of progressive automation including Arduino Uno, Web of Things and Remote Sensor Organization is proposed. The element of this paper is the improvement of a framework is utilized to control temperature, moistness, mugginess and furthermore the mediation of creatures through sensors to execute crops in the farming area utilizing the Arduino board in case of any distinction, following ecological conditions utilizing 3G/4G/5G/Wi-Fi modules are considered as major ingredient in achieving the yield of productive crops, and sending the SMS notification and an application notification designed similar towards producer's smart phone making use of 3G/4G/5G/Wi-Fi modules. There are a few examination issues identified with sensors and their organizations due to the meaning of sensor innovation. A portion of the significant sensor network issues for which a few arrangements have been proposed by scientists are energy requirements, restricted handling power, little memory and information security. The work fundamentally centers in investigating the requirement for remote sensors in various fields of agribusiness additionally tells the new progression in the IoT market, need of robotization in horticulture area likewise what all difficulties ranchers are confronting utilizing IoT.
\end{abstract}

Keywords:- Internet of Things, smart Agriculture Framework, Wireless Sensors Network, Smart farm

\section{Introduction}

Ranchers need agrarian data and appropriate information to settle on educated choices and to fulfill educational necessities. In horticulture area with the development of information the executive framework, enquiries of ranchers can be replied for the assistance of media which is effectively available. Innovations now overcome the obstacles by utilizing remote innovation, organizing, portable and so on to conquer the utilization of vitality, force and cost expending types of gear which was useful in the horticultural turn of events. The improvement of ICT in different areas has driven considerable enthusiasm in increasing ventures by private parts towards ICT production in agricultural science research.
There have not been any noteworthy mechanical progressions being made in farming division when contrasted with different parts. Horticultural framework should be checked all the time. The utilization of the created structure is to reduce garbage via robotizing the whole agrarian framework. Considering seniority of individuals, recent automation is giving trump card. Internet of Things has now started to take on an important job in everyday life in recent years, expanding our observations also competency to change society in which we are living. Especially the agriculture \& mechanical also ecological farm bear on parcels in pair distinctive and benchmark. What's more, in giving data at end to customer/buyer next to starting point its characteristics of the item. With the context, this work expects to apply loTs for PC maintenance advancement of farming. A foreside streamlining of horticulture, establishment of Wireless Sensor Network (WSN) as on the province has developed feasibility and efficient for the farmers. It may help to determine farm adaptable, including soil position, barometric conditions, along with flora or creature biofuel. Furthermore during item transport for testing and monitoring variables, including temperature, humidity \& moisture. In addition, WSN is useful to screen and monitor variables which affects flora extension and product. These can be useful to assess optimal time for gathering, which farmers are increasingly acceptable of which circumstances, disease distinction, and benchmark apparatus. [4, 9, 13]

Present work, we concentrate on information in the yield fields consisting of temperature, stickiness, and soil dampness. We need information stockpiling and a way to deal with finding information from the information obtained and communicating with the customer in order to establish an appropriate structure. As an online application, a database system will be organized and modified. The data put away will be used for dynamic monitoring of the programmed watering of harvests. The agricultural information will be studied in order to advance and turn the soil around and to forecast the water demand for harvests later on. In agrobusiness, knowledge mining was used to find information. In general, the rules of approach association were used to find fascinating relationships with huge databases between variables. It breaks down and establishes secret relations between the characteristics of agricultural understanding, fostering logical dynamics. Also, the purpose of current efforts is constructing and updating a WSN used for detectors for farm to harvest, in addition knowledge of the WSN system board used an advanced cell phone and web application to communicate with the consumer. The proposed system would promote the production of blended harvests and assist ranchers who have access to the framework whenever and wherever. 


\section{Related Work}

The significant test recognized in the present space is to give ranchers needed data and auspicious support. In order to support economical horticulture, it is difficult to track down knowledge as it may not exist or be comprehensive to find, the application used in web is astute thinking of sound answers to develop course and obtain data on maintainable horticultural methods.

\subsection{Application of IoTs:}

Some studies developed an ontological structure for multimatching and method combination. ASP.NET, C\# was used to organize yielding substances in the framework. For the design of the system theory, XML was used. Here, cosmology based data recovery frameworks helps ranchers by recovering and incorporating a few data together to meet the data necessity of the inquiries. Exact client setting data is given to ranchers the assistance of a particular philosophy [10].

The Researchers proposed a solid conveyed versatile engineering to give ranchers auspicious data. The proposed configuration depended upon the utilization of sprinkle quality from a multi-farmland point of view for planning a threefold cloud-empowered interface of designing. The previously mentioned structure empowers ranchers to get to different data by means of Wi-Fi or 3G. Cosmology depend on employment exhibiting genuine downsides too for the most part, it accumulates in building a information base to address inquiries but neglects to speak to the full web interpretation of expansion can be utilized in the field. In the field of agribusiness, there are a few current alert frameworks created which integrates: eSagu that consolidates counsel from specialists to improve ranch yield and profitability. Agrisnet is an electronic interface that, with the help of an adaptable data bank, gives fitting data on seeds and composts. Karshaka Information Systems gives data on yield creation in the KKP development; advertise cost and accessibility with general measurements. $\mathrm{m}$ Krishi is portable application helping ranchers with visual and sound intends to free their inquiries from ranchers. [7] The present systems show efficient designs to provide ranchers with simple field data over $3 \mathrm{G}$ or Wi-Fi. Disconnected connections between ranchers are empowered via Bluetooth by integrating CGM modules over IoT, the generated awareness of frameworks is enhanced by a significant edge. Utilization of detectors in cloud Computing and IoT applications is heavy still lumbering to incorporate, which makes the equivalent a big concern. It may be unfortunate in the event of an accidental accident, relying aggressively on technologies such as GPRS, GPS, 3G, Wi-Fi, etc. The above-mentioned burdens make a real mistake in resolving the existing testing conditions of rustic individuals in the field of agribusiness.

IoTs have been implemented in several reviews over the last few years, as discussed in many research articles. Using horticultural engineering is useful in increment of crop production or structured and minimizing its costs. Utilization of WSN in exactness agribusiness allows ranchers to decide on better also very highly knowledgeable options in a measurable way. [14]

A new integrated data system (IIS) for provincial ecological checking was proposed by Fang et al. and the board, in view of IoT, to develop skills in complex assignments. With a contextual investigation on territorial environmental change and its biological reactions, the proposed IIS consolidates loTs, Cloud Computing,
Geoinformatics (RS, GIS, and GPS) and e-Science for natural observation and the board. In addition, loTs were used in the agro-modern creation chain. [13]

The application of loTs to the agro-modern engineering production chain. Researchers suggested a advanced engineering based on the loTs notion, consolidating remote and transmitting explicit sensor gadgets alongside replication of weather situations so as to achieve the advancement in winery grapes. [4]

The introduction in the development framework for agribusiness dependent on loTs. In that analysis, loTs servers were finished with circulated loTs after and after the entire farming development. A data revelation system was also intended to update, capture, normalize, supervise, locate, and query horticultural business knowledge. Some researchers proposed a value-driven Business-Technology Joint Structure System to provide the latest customer/buyer with information on the origin and properties of the item. [5]

The proposed online choice of emotionally supportive network talking to the WSN to plan a water system for the olive groves. Already stated the reason, creators used detectors to compute humidity, sun-oriented radiation, temperature, and downpour. System checked the control of temperature and soil dampness using an electronic gadget (Arduino) and used an Android-based cell phone app for adaptability and usefulness. In minimal effort, focal points and adaptability for farming control were found to be interesting for expensive parts, such as very good quality PCs Luan et al. (2015) planned and developed an engineered framework that coordinated dry spell observation and estimation, and a water system sum that determined on a loTdependent stage, cross-breed programming, and equal registration. [7]

Some researchers focused on water system structures utilizing WSN for gathering condition data and controlling the water framework system through a phone. Kaewmard and Saiyod (2014) gave an upheld reaction to automation of agribusiness to acquire information from crop harvests or for natural estimations. Manufacturers have innovated reduced assessment advancement, including a dirt suddenness sensor, an air tenacity sensor, and an air temperature sensor. [11]

The structures for the control of different layer soil temperature also mugginess in farmland utilizing WSN for improvement of water use and to assemble fundamental data on soil water entrance assortments and the sound water framework.

\section{Development and Realization of Device}

Information assortment, checking and assessment of the framework bring about figuring out which approach is powerful and where these adjustments are generally required. Along these lines, ICT drew in mediations in farming division are more efficient than the regular techniques. Specialized and money related guides are crucial requirement for the ranchers to become adjust comprehensive and viable technique. These difficulties handled by ICT used data scattering version for sharing the information that improves the profitability, social and ecological sustainability of ranchers and ranchers' networks. The basic areas of engineering represented the information base and the control framework. Here, the main segments are explained in short.

\subsection{Foundation of information:}

The Information Based system is designed in storing enormous tedious and disbursed data to assist ranchers, even 
a person with no previous cultivation information. In any case, discovering right data in a fitting way is troublesome where giving pertinent information ought to be circulated in a composed and complete way, yet additionally in total way. The information based foundation permits adjusting the adjustments in farming for a superior augmentation what's more, including warning administrations.[22]

\subsection{Acknowledged Inputs:}

The Information based system information modules on development measures, show information, crop structure and geospatial data. Cultivating procedures remember the accepted procedures for cultivating to accomplish greatest yield and involves bug and ailment controls included with stage based cultivating techniques. Market data incorporate different cost info's, venders, vendors, distribution centers, reserves, credits, committed site, call focuses, E-learning and market accessibility. Yield structure includes data about harvest breed, crop factors, bug, illness data and soil supplement necessities. Geospatial information is utilized to import the nuances of the climate and the content of the water table to help farmers select their most efficient harvest. It is likewise used for setting the farm structure as indicated by the region assortment of the farmer. [22]

\subsection{Information acquisition:}

Securing information essentially refers to the way in which data is acquired, investigated, appraised and reviewed amongst the advantageous of available reliable strategies. In this work, information obtained from reliable origins in developing a model for coordinating ranchers, agricultural offices, the Ministry of Agribusiness, Agricultural Universities and organizations alongside the rest of the API administration.

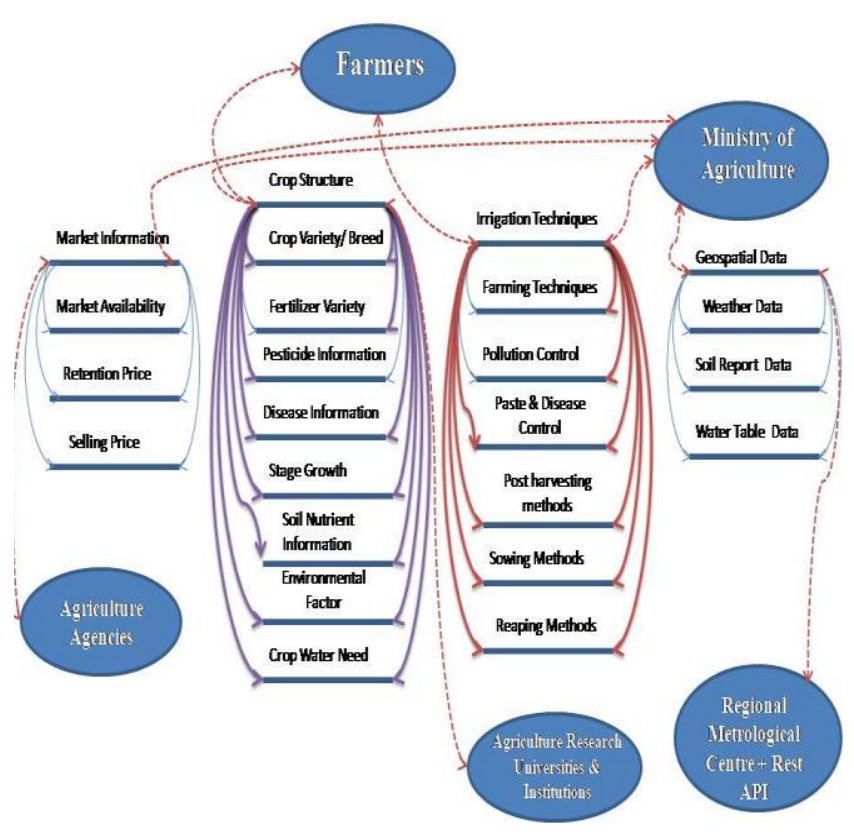

Fig 1. Model for information securing including the design of crops. [22]

\subsection{Information Movement:}

The Yield Information movement model uses a conceptualized organization to talk to the knowledgeable stream and provide ideal information to change the varying climate situation. The information stream module clarifies how the information streams starting with one module then onto the next and it just as clarifies how every component which is associated. Fig.2. tells Information flow model of the created framework for different stages.

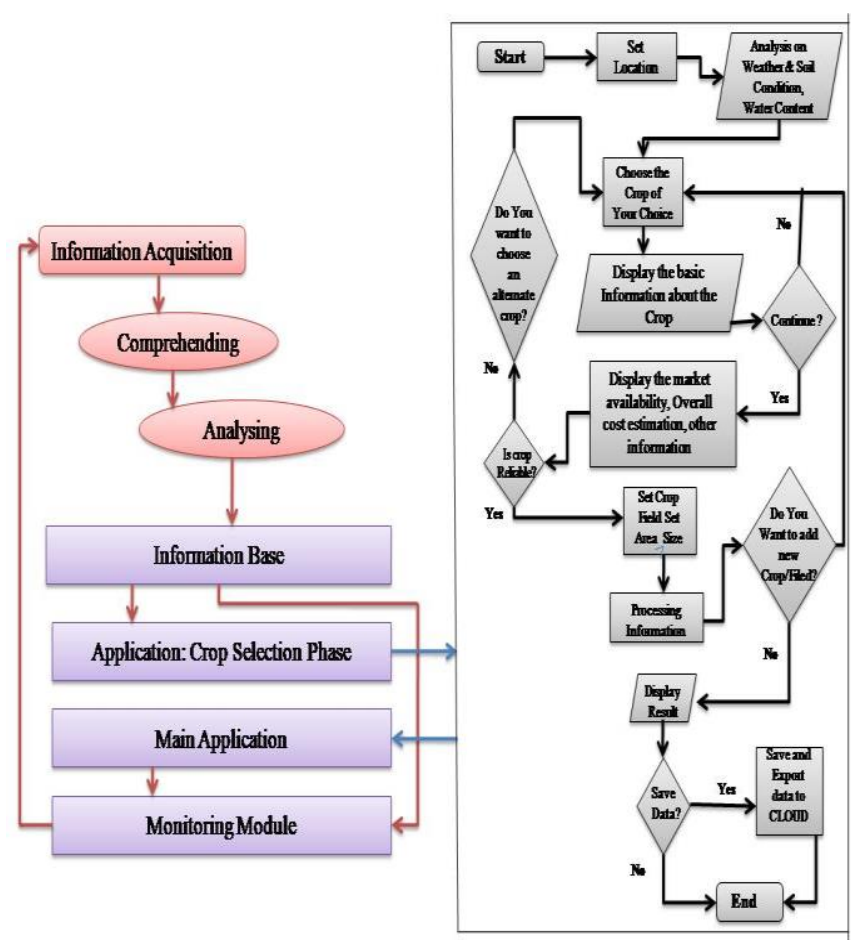

Fig 2. Application Information Flow Model.[21]

\subsection{Interface Observation:}

\subsubsection{Requirements for hardware:}

The Texas Instrumentation module CC3200 Launh Vehicle also Arduino UNO Ethernet cable boards habituated to implement observation modules. The above said instruments and supporting devices are collecting the field information in real time.

Temperature and Humidity Sensor DHT11:- The DHT11 Dampness and Hotness detector consist of three principal parts. A resistive mugginess sensor, a negative temperature coefficient thermistor (temperature estimation) also a 8-cycle microcontroller which changes over simple notations from two sensors and imparts a solitary mechanized sign.

Soil Moisture Senor: - The manufacturing is more when soil dampness is lacking (for example the arena is dried) and the yield is low. Simple interface can be utilized for precise yield. Sensor-The yield of the ball drift fluid level depends fair and square of the fluid.

Attractive Float Sensor: - The floating detector gadget utilized in distinguishes the measure of a fluid in the vessel. The drift Sensor is opening and closing the electromagnetic regulator.

BH1750 LDR resistor/Optical Light Intensity Sensor Module 
A relay having four channel of $(5 \mathrm{~V})$ for AC/DC exchanging is utilized to control the valves by initiating an $\mathrm{AC}$ engine $(220 \mathrm{~V})$

\subsubsection{Requirements for apps:}

Energia MT is an easily accessible free demo type hardware phase that adapted by Texas Instruments is useful in writing, collecting and executing the inserted c codes, the Arduino software development condition needed to compose secret writing in Arduino programming speech to educate Arduino users. Blynk is a phase for iOS and Android applications to screen Arduino, Raspberry $\mathrm{Pi}$ and Internet inclinations. It's a high level dashboard where you can work with just moving devices for a functional interface for any sort of mission.[23]

\subsubsection{System Architecture:}

Monitoring of Interface Module:The monitoring process is made up of the main skills and functions of the application. Mankind who are using this is licensed from the knowledge base utilizing the conclusion-building framework, agricultural comprehension evaluation of different programs.

Recollector: System is utilizing in helping farmers to remember the harvesting, showering of composts, pesticides, and water system plans. It tells the client consistently by means of a programmed SMS notice dependent on info boundaries from the information base.

Observing Flora Widening: Various phases of development onto the information basis are utilized in computing a relating period of development. The towering of the plant is discovered utilizing the planning plot picture of the flora and this stature utilizing to anticipate if crop is fulfilling the prerequisite.

Water system Planner: It permits a progression of plans in an example to inundate various pieces of the field to accomplish beneficial yields. It likewise uncovers field information as dry and inundated fields as an opportunities for following. Rotational or ceaseless stream is intended to flood the field dependent on the assessment of harvest water needs.

Disaster check: According to the climate conjecture obtained from Yahoo climate API, the water system plan and the field assortment are adjusted. It is additionally used to screen abnormal field activities, for example, prompt terminating, and so on.

Issue Identifier: This characterizes the issue when the water system framework is misled, the engine issue. It generally characterizes where the issue has emerged. For instance, there is no requirement for providing orders to the peripherals on account of no force supply, while the client ought to be educated regarding the force issue.[20]

Count of Aqua requirement: The measure of aqua necessity in gathering aqua scattering between vanishing and happening is characterized the harvest aqua need (ETc). The harvest water need is oppressed for a uniform yield, infection free, dynamic having ideal ground quality. In a matter of subsequent, Evapotranspiration assesses the aggregate sum of water crop need the characteristic development comparing with the neighborhood climate position and term of the plant life cycle. Calculation outlined in assessing the demand of water. [1]

\section{Calculate Evapotranspiration for particular crop ET0 [1]}

ETo $=0.0023 * \sqrt{ }($ tmax - tmin $) *(\operatorname{tmin}+17.8) * \operatorname{ExTR}$

Calculating the radiation for high terrestrial region [3]:

$\operatorname{ExTR}=1364 *(\operatorname{Rav} / R)^{2} \mathrm{~W} / \mathrm{m}^{2}$

$\left(\mathrm{R}_{\mathrm{av}} / \mathrm{R}\right)^{2}=1.00011+0.034221 * \cos (\beta)+0.001280 * \sin (\beta)$

$+0.000719 * \cos (2 \beta)+0.000077 * \sin (2 \beta)$

Where $\beta=2 \pi \mathrm{n} / 365$ radians and $n$ is the day of the year.

2. Crop Factor calculation $(\mathrm{Kc})$ depending upon the phases of the plant increment.

3. Et $($ Plant $)=E T o^{*} K c$.

\section{Determining SAR (Aqua stored in the Source Area)}

5. Amount of percolation and seepage losses (PESE) based on the soil type is to be determined.

6. Evaluating the quantity of Aqua required forming a aqua surface: WLayer depend on the phases of the extension.

7. Compute Essential Precipitation of the land depend on yearly rainstorm. (effR)

8. Enumerate Plant aqua requirement:

$W N=$ Etcrop $+S A R+P E S E+$ Wlayer - effR.

9. The Calculation of Continuous Flow and the Rotational flow movement.

Contflow $=($ WN/8.64 $) *$ hectersize.

Rotflow $=(24 / H) *(7 / D) *$ Contflow.

Visual Monitor: The inherent light of the Sun is the ideal frequency parity needed for vegetable widening; also it can useful to support plants along with the use of counterfeit light. Developing illumination is useful to promote crop widening in the place where no enough sunshine or where the hours of sunlight are lower. For the most part, this application is used to boost the development of the plant in winter locations/months. Here, the Light Potency Sensor observes the sunlight and whenever it decreases down the limit quantity, enhancement of illumination is worn to animate widening of the crop.

Well Dry Check: Such system model is used to examine if the deep well is dried obtaining contribution with the hub of the dirt dampness sensor, informing the customer when the value goes below as far as possible and the customer can respond to which related operation can be performed by turning on the engine, such as filling the well.

Field Dry Check: It is quite familiar with the pervious component it utilizes ground dampness detector hub, which tells client if the field is complete dry or not.

Distinguish form of dirt also lack of soil: All dirt has a water keeping limit of its own. The type of soil can be recognized 
and if the determined soil is compared to the constant information with already told sets of qualities for the information base.

\subsubsection{Terminology:}

$\begin{array}{ll}\text { ETo } & \text { Recommendation Intake Evapotranspiration } \\ \text { Tmax } & \text { Highest Hotness during working day } \\ \text { Tmin } & \text { Lowest Hotness during working day } \\ \text { Tmean } & \text { Mean Hotness during working day } \\ \text { Rav } & \text { Mean distance from Earth to Sun }\end{array}$

R Real distance from Earth to Sun

Kc Yeild Component

WN Aqua Need

$\mathrm{H} \quad$ No. of Hours

D Count of Days

SAT Soaking of the Root Zone

PESE Quantity of Filtration and discharge Deprivation

WLayer Aqua layer

effR Effective Rainfall

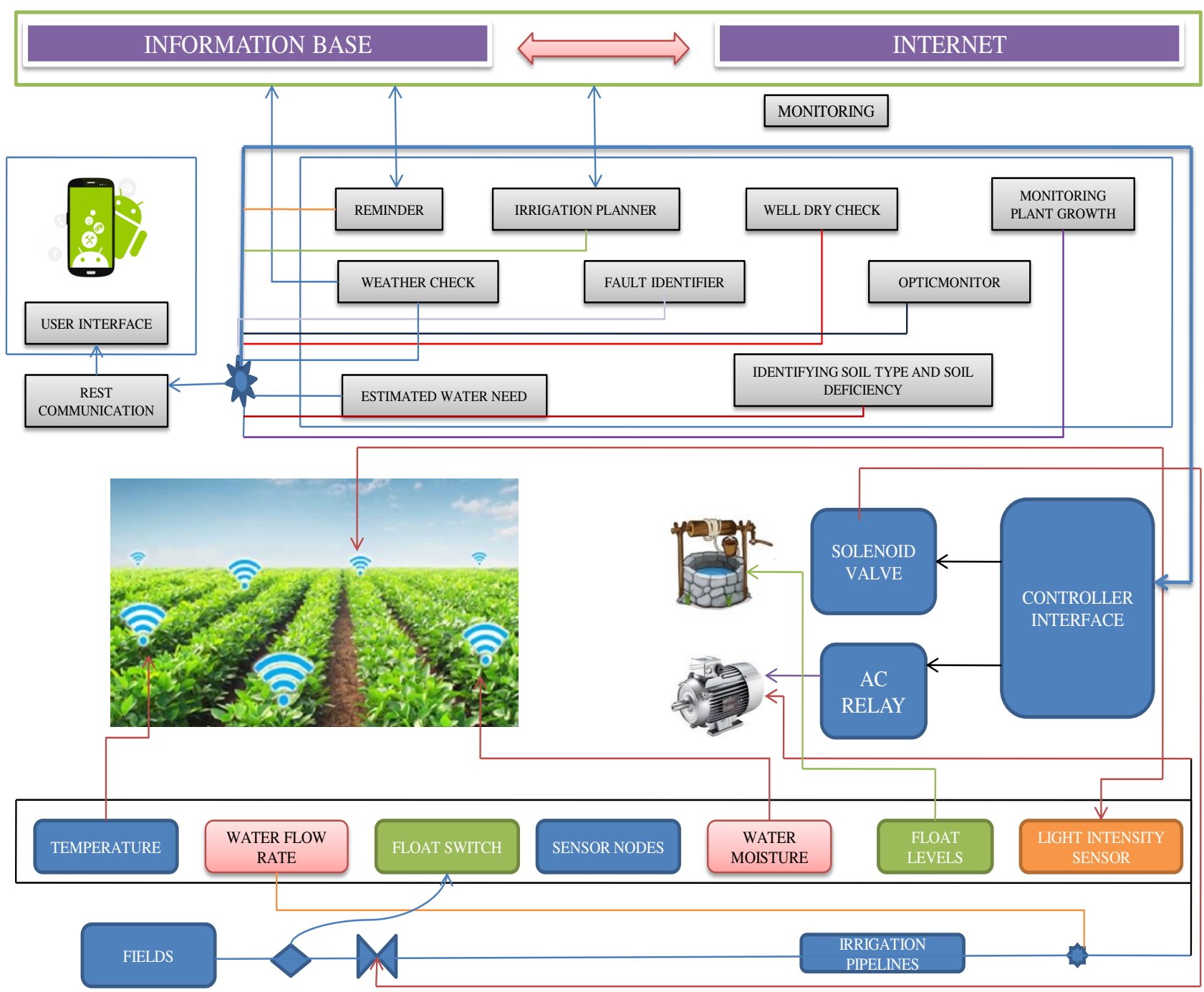

Fig 3. Architecture of e-Agriculture Module for monitoring [20,23]

\section{Conclusion:}

IoT has been utilized in farming for improvement of crop yields, improve the quality and also decrease costs. We hence proposed the use of WSNs to water system crops. In this work. Ranchers need assistance during various phases of yield development and the direction ought to be given at the opportune time. Ranchers are enduring a great deal monetarily, socially and strategically. Different difficulties in rural space are distinguished and a design was encircled gathering the previously mentioned difficulties. Information base is organized with different yield subtleties which talk about information obtaining, stream, different info like market openness, geospatial data and environment assumptions. Perception incorporates modules, for example, extra segment, perception of plant improvement at various stages, water framework coordinator, crop superiority analyst, and debacle control and issue identifier. The fly off, water loss technique is making use to decide the aqua needs of a plant everyday with the assistance of a devised figuring. A comparative report was drawn up between various applications and the current system, considering various perspectives, for example, the data base, perception of modules, efficiency and steady quality.

\section{References:}

[1] FAO Document repository, Chapter 3- Crop Water needs. http://www.fao.org/docrep/s2022e/s2022e07.htm

[2] Jincui Kang, J. G. (2012). Application of Ontology Technology in Agricultural Information Retrieval.2nd International Conference. Water management, 19-28 (2010). [3]University of Oregon - Solar radiation Basics. http://solardata.uoregon.edu/SolarRadiationBasics.html 
[4] Capello, F, Toja, M., Trapani, N., 2016. A real-time monitoring service based on industrial internet of things to manage agri food logistics. In: Xth International Conference on Information Systems, Logistics and Supply Chain, pp. 1-8. [5] Chen, KT., Zhang, H.H., Wu, T.T., Hu, J., Zhai, CY., Wang, D., 2014. Design of monitoring system for multilayer soil temperature and moisture based on WSN. In: International Conference on Wireless Communication and Sensor Network (WCSN).IEEE, Wuhan, pp. 425430, https://doi.org/10.1109/WCSN.2014.9.

[6] Fang, S., Da Xu, L. Zhu, Y., Ahati, J., Pei, H., Yan, J., Liu, z 2014. An integrated system for regional environmental monitoring and management based on internet of things. IEEE Trans. Ind. Inform. 1015961605

[7] Fourati, MA, Chebbl, W., Kamoun,A.,2014. Development of a web-based weather start irrigation scheduling. In: Information Science and Technology (CIST), 2014 Third International Colloquium in IEEE, pp. 37-42.

[8] Richard k. Lomotey , Ralph Deteres, Management of Mobile Data in a Crop Field Year: 2014, Volume: 1, Pages:100-107 doi:10.1109/MobServ.2014.23

[9] Hashim, N., Mazlan, S., Aziz, M.A., Salleh, A., Jaafar, A, Mohamad, N., 2015. Agriculture monitoring system, a study.0.Teknologi77,53-59, https/doi/10.11113/7.4099

[10] Susan Ellakwa, El-Sayed El-Azhary, Passent Elkafrawy.2012.Integrated Ontology for Agricultural Domain September 2012 International Journal of Computer Applications 54(2):46-53 doi: 10.5120/8542-2088

[11] Kanen, O., Khrij, S., El Homini, D. Vichweger, c. Jmal, M.W., Abid, M, 2014. Precision irrigation based on wireless sensor network. IET SC. Meas. Technol. 8, 98-106. https//doi.org/10.1049/iet-mt. 20130137

[12] Luan, Q. Fang, X. Ye. C. Liu Y 2015 An integrated service system for agricultural drought monitoring and forecasting and irrigation amount forecasting In 23rd International Conference n Information IEEE, pp. 1-7. Lukas, Tanumihardja. W.A. Gunawan, E, 2015. On the application of lot: monitoring of troughs water level using WSN. In: ConferenceonWirelessSensors

(ICWISE).IEEE.pp.5862. https://doi.org/10.1109/ICWISE

[13] Kodali, RK, Rawat, N., Boppana, L, 2014. WSN sensors forprecisionagriculture.In:Region10 Symposium .IEEE, pp 651- 656. http://doi.org/10.1109/TENCONSpring 2014611

[14] Ojha, T., Misra, S., Raghuwanshi, 2015. Wireless sensor networks for agriculture the state of the art in practice and future challenges. Comput. Electron. Agric. 1186684 Patuja, R.Verma, H. Uddin, M.. 2013, wireless sensor network for greenhouse climate control. IEEE Pervasive Comput. 12, 49 58.
[15] Run, J., Shi, Y., 2016. Monitoring and assessing fruit freshness in loT-based E-commerce de livery using scenario analysis and interval number approaches. Inf. Scl. 373557570 https://doi.org/10.1016/j.ins2016.07.014.

[16] Pang 7, Chen, Q., Han, W., Zheng, L. 2015. Valuecentric design of the internet of things solution for food supply Chain value creation, sensor part fobo and information http://doi.org/10.1007/10796-012-9374-9

[17] Sarangl. s., Umadikar, J., Kar, S. 2016. Automation of agriculture support systems using Wisckar case study of a crop disease advisory services. Comput. Electron. Agric. 122, 200210 http://doi.org/10.1016/j.comnag

[18]Kaeward. N. Salad. S. 2014. Sensor data collection and irrigation control on vegetable crop using smart phone and wireless sensor networks for men form. in Conference on Wireless Sensors (CWISE), IEEE, pp. 106-112.

[19] Didnchs, AL, Tabacchi, G., Grunwaldt, G., Pecchia, M., Mercado, G., Antivilo, EG, 2014 Low-power wireless sensor network for frost monitoring in agriculture research. In Proceedings of IEEE Biennial Congress of Argentina, pp. 525 530.

[20] Richard K. Lomotey, R. D. (2014). Management of Mobile Data in a Crop Field. 2014 IEEE International Conference on Mobile Services (pp. 100-107). IEEE

[21] Fredrick AWUOR, K. K. (2013). ICT Solution Architecture for Agriculture . IST-Africa 2013 Conference Proceedings Paul Cunningham and Miriam Cunningham (Eds) IIMC International Information Management Corporation, 2013. Africa.

[22] Prof.B . B.Kotame, Prof. N.L.Chokhar (2017), A Survey on Advancements in Agriculture and Food Technologies. International Journal for Research in Applied Science \& EngineeringTechnology(IJRASET)http://doi.org/10.22214/ijr aset.2017.42

[23] I Mohanraj, Kirthika Ashokkumar, J Naren "Field monitoring and automation Using IOT in agriculture domain" Procedia computer science, 2016. 


\section{Figures}

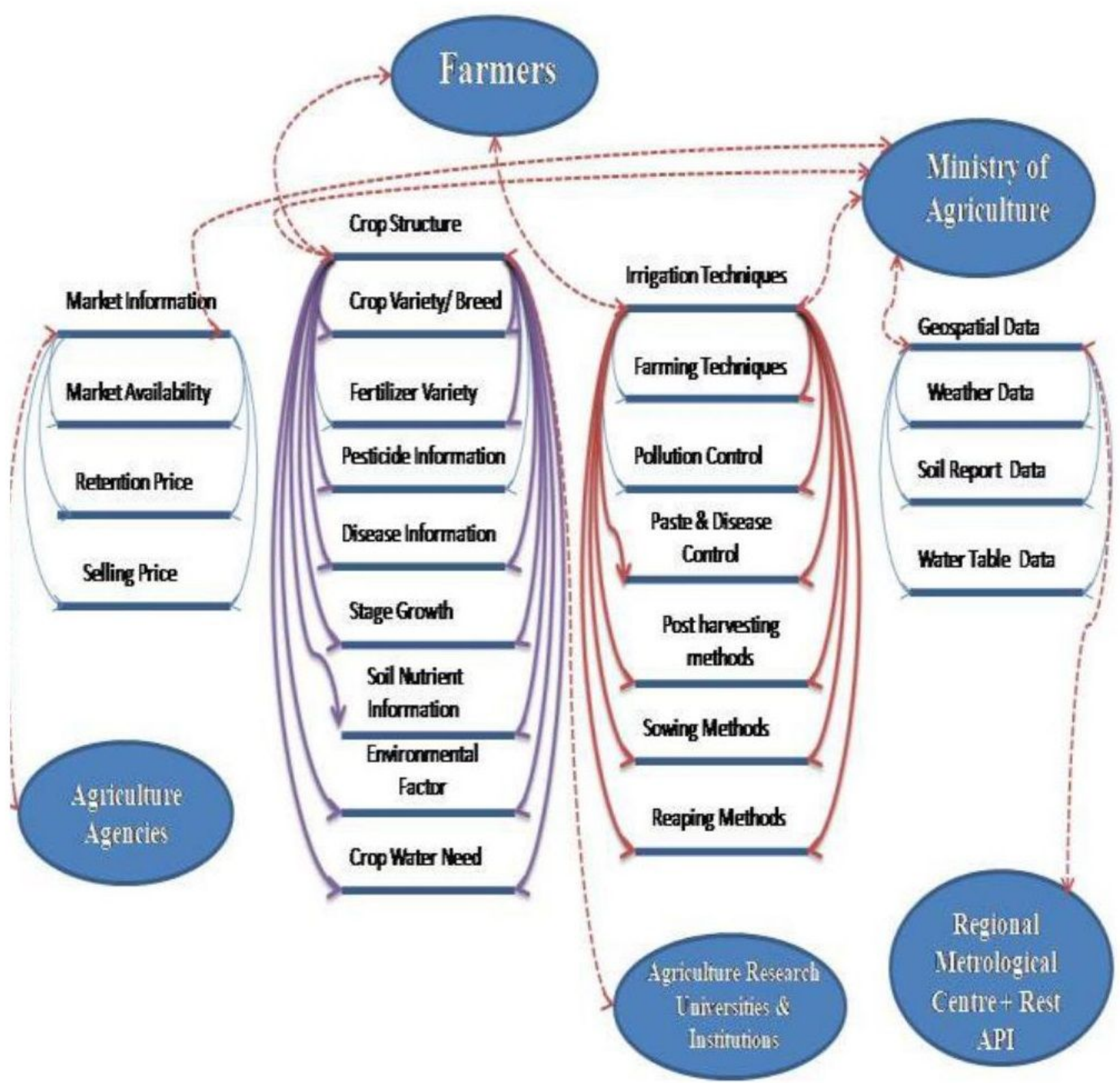

Figure 1

Model for information securing including the design of crops. [22] 


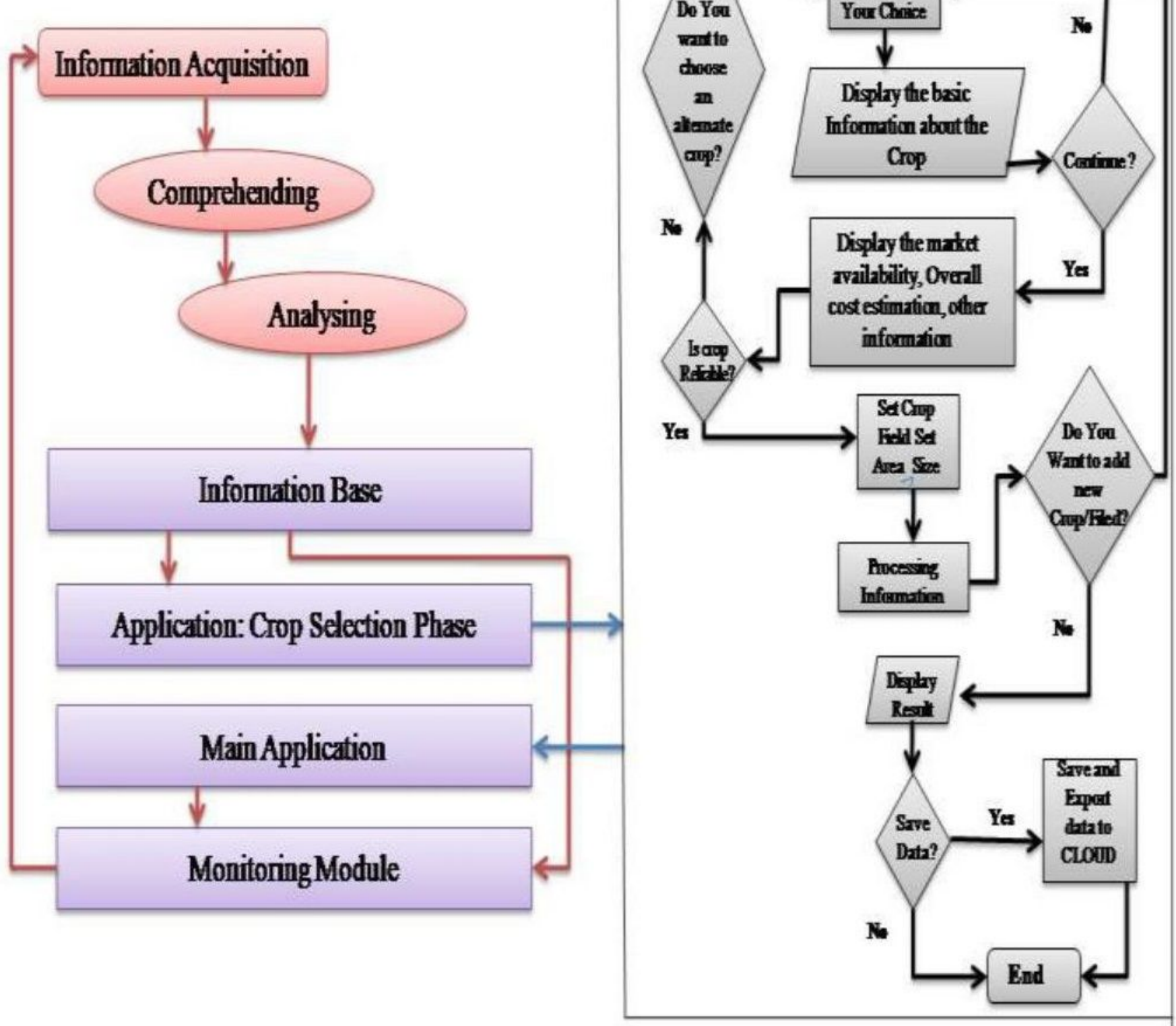

Figure 2

Application Information Flow Model.[21] 


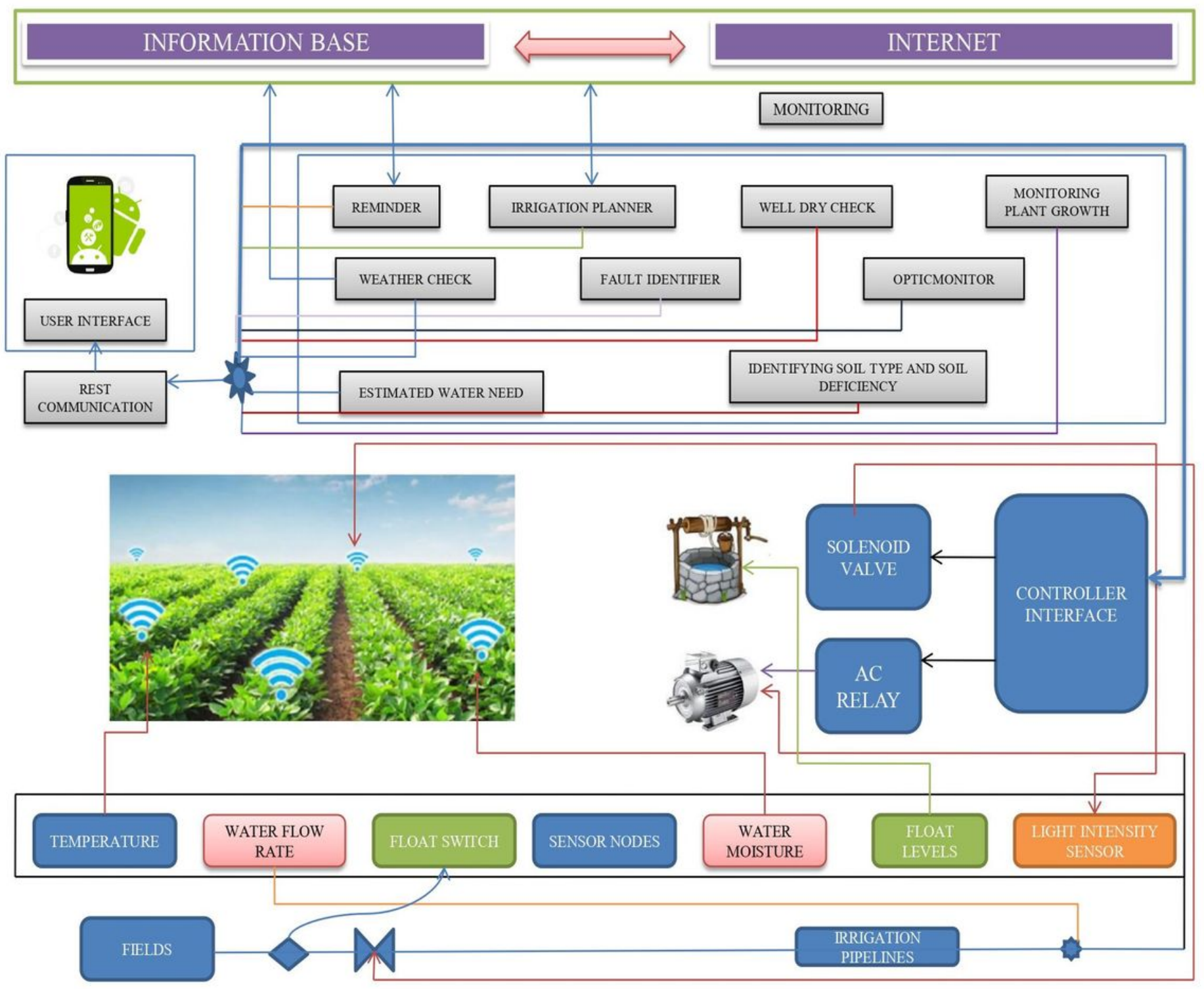

Figure 3

Architecture of e-Agriculture Module for monitoring $[20,23]$ 